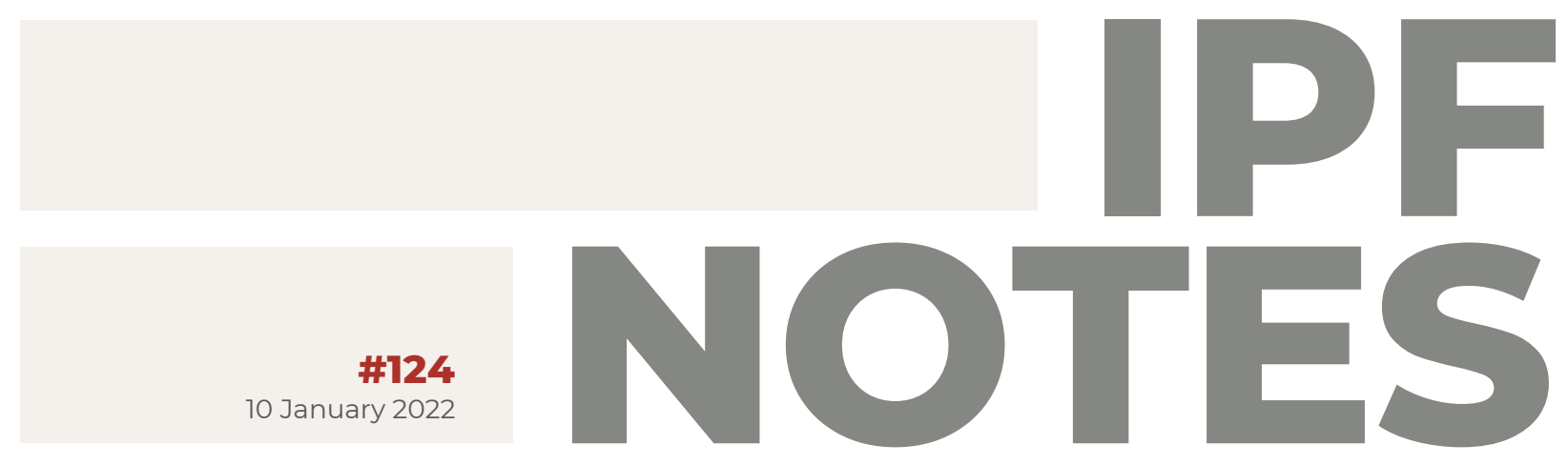

\title{
National benefit for the elderly
}

\author{
Marijana Bađun, Ivica Urban \\ Institute of Public Finance, Zagreb
}

National benefit for the elderly was introduced by the Government in January 2021 with the purpose of providing social security to persons over the age of 65 who failed to secure income for their old age and are unable to earn it in another manner. According to figures presented in the Draft Act on the National Benefit for the Elderly, around 19,700 persons were estimated to be eligible for this benefit in 2021. However, the latest data of the Croatian Pension Insurance Institute show a much lower number of beneficiaries only 5,658 persons received the benefit in November 2021. The present note explores the potential reasons why the number of beneficiaries is lower than expected.

The Strategy for Social Welfare for the Elderly in the Republic of Croatia for the period 2017-2020 provided for the introduction of the national pension for the elderly who are not eligible for pension on 
the basis of previous labour and paid contributions. However, the Government abandoned the "national pension" idea and introduced the "national benefit for the elderly" (hereinafter NBE) instead in 2021.' The Draft Act states that the benefit is intended for elderly persons "who, during their working age, failed to secure income for their old age, for objective or subjective reasons". The benefit is allocated by the Croatian Pension Insurance Institute (HZMO) and is disbursed through commercial banks. The monthly amount of the benefit is HRK 800 . The funds are secured in the State Budget. ${ }^{2}$

The draft act also states that around 60,000 persons over the age of 65 in Croatia do not meet the minimum pension eligibility requirements. The Croatian Government estimated that around 19,700 persons would be eligible for NBE in 2021 based on the defined conditions, with this number rising to 21,840 persons in 2022. The estimated cost of the measure amounted to HRK 132 million in 2021 and HRK 186 million in 2022. However, latest available HZMO data show that in late November 2021 the benefit was received by only 5,658 persons, while in late January the number of beneficiaries stood at 3,091. Around two-thirds of beneficiaries are women. Based on the HZMO press releases, we can calculate that between January and November 2021 this benefit cost the State Budget HRK 42.7 million.

${ }^{1}$ The Act on the National Benefit for the Elderly (Official Gazette 62/20) entered into force on 1 January 2021.

2 The monthly amount of the national benefit for the elderly is adjusted on 1 January of every calendar year, starting from 1 January 2022, taking into account the consumer price indices change rate in the previous year relative to the year before that, according to the Croatian Bureau of Statistics data. 
Eligibility conditions for receiving national benefit for the elderly

According to the Act on the National Benefit for the Elderly, the benefit may be granted to a Croatian citizen who, immediately before applying for the benefit, has reached the age of 65 and resided in the territory of the Republic of Croatia for twenty years without interruption. Besides the principal requirement above, applicants must also comply with the following conditions:

- they are not pension beneficiaries or insured persons covered by mandatory pension insurance,

- they are not entitled to the guaranteed minimum benefit (GMB),

- the net income of the applicant's household in the previous calendar year per household member does not exceed the monthly amount of the NBE,

- they are not entitled to accommodation services according to social welfare regulations,

- they have not concluded a contract of support until death or a lifelong support contract in the capacity of a supported person.

A household is defined as a family or another community of persons living together and sharing life expenses, regardless of their kinship. Net income is equal to all monetary income earned through labour, pension, receipts from assets or earned in any other manner in the country or abroad, reduced by the amount of paid taxes and surtaxes. Allowances for aid and care, disability allowance, physical impairment allowance and other benefits not liable to personal income tax are not counted toward this income. The NBE is not liable to assets test. 
A pension beneficiary and GMB beneficiary can be eligible for NBE on the condition that they request their pension or their GMB to be terminated. Below we analyse these options.

\section{National benefit for the elderly or guaranteed minimum benefit?}

GMB is part of the social welfare system and is intended for persons that do not have sufficient means to meet their basic life's necessities. It is not dependant on age or long-term residence in the Republic of Croatia. GMB is a benefit allocated by implementing a relatively strict income and assets test procedure. According to statistical data collected by the Ministry of Labour, Pension System, Family and Social Policy, a total of 57,335 persons received GMB in 2020 , of which 6,991 were over the age of 65.

GMB beneficiary waiving the benefit in favour of NBE is at an advantage since the NBE does not entail assets test. However, income assessment is still conducted, the difference being that the results are not submitted to the social welfare centre but rather to the competent HZMO branch office. Since the monthly amounts of both of these benefits are relatively low and any difference may be substantial, we should determine which of these two benefits pays higher amounts. NBE and GMB use different formulas for verifying income levels and their monthly amounts differ too. Some households may receive higher benefits if they decide to switch to NBE, while others may receive more if they remain loyal to GMB.

For instance, a single person over the age of 65 (i.e., person incapable for work living in a one-person household) would receive HRK 920 of GMB, which is HRK 120 more than the NBE amount. It should be highlighted that in the Croatian social welfare system 
GMB eligibility often serves as a "free pass" for various other benefits, especially at the local level (e.g., housing and fuel allowances). For this reason, the overall loss for an NBE beneficiary waiving their GMB right may be even greater. Let us consider the example of a two-person household in which neither spouse earns any income. They are both eligible for NBE, thus bringing the household income up to HRK 1,600, which is substantially higher than HRK 960 they would receive as GMB. ${ }^{3}$

\section{National benefit for the elderly or pension?}

Pension income is not liable to income assessment, whereas this procedure is mandatory for NBE. Income testing can cause uncertainty and suspense for a potential beneficiary. In addition, a person may be in doubt regarding the types of income covered by income assessment. In addition, if the household's income increases for one reason or another (e.g., for doing occasional work for a fee or due to employment of a working-age household member), the persons can find themselves in the situation that they are no longer eligible for the benefit.

Latest data collected by HZMO concerning pensions earned pursuant to the general regulation (Pension Insurance Act), excluding international agreements, show that 2,969 beneficiaries received a pension lower than HRK 500 in October 2021, while 19,383 beneficiaries received between HRK 500 and 1,000.

\footnotetext{
${ }^{3}$ The HRK 960 rate is obtained by multiplying the number of adult household members (2) and the amount granted to each adult household member (HRK 480). Basic information about the GMB is available at the following link.
} 


\section{Other factors affecting the number of beneficiaries of the national benefit for the elderly}

One of the factors potentially affecting the relatively small number of beneficiaries of NBE is lack of information. The introduction of the benefit was accompanied by a media awareness campaign, but its public impact may not have been as desired. Another potential reason may lie in the manner in which the process of determining eligibility is initiated. To initiate this process, a potential beneficiary should first obtain a form from HZMO's website or at an Official Gazette stationery shop, complete it and submit it to a local HZMO branch office or electronically via the eCitizen system. However, it should be kept in mind that the potential beneficiaries of the benefit are older persons usually with limited mobility, some of them living in remote areas and having no one to assist them with submitting the request. Finally, the benefit is disbursed through commercial banks, whose branch offices or cash machines are not evenly spread throughout the country. ${ }^{4}$

\section{Conclusion}

The Government's intention when introducing the NBE was to reduce poverty rates of the $65+$ population, primarily of those without or with very low income. Since the number of applicants for the benefit was around 14,000 lower than the projected number, it seems that this measure failed to achieve its purpose in full. The competent Ministry of Labour, Pension System, Family and Social

\footnotetext{
${ }^{4} \mathrm{~A}$ beneficiary may authorise a proxy to receive the benefit on their behalf. The proxy mandate should be delivered to HZMO and is valid for one year.
} 
Policy is to determine why this is the case, while the present note indicated several potential reasons. One group of reasons pertains to lack of information provided to potential beneficiaries on the very existence of the benefit and the inability to exercise their right due to application and disbursement issues. The benefit has been in force for only a year, and it might take more time to become more entrenched. This is supported by the fact that the number of beneficiaries has been gradually rising each month. The second group of reasons pertains to the legislator's expectation that some of the current pension or guaranteed minimum benefit beneficiaries would waive their current benefits and switch to the new benefit, which turned out not to be the case. In addition, we should also mention the possibility that the projections used when drafting the act overestimated the total potential number of beneficiaries. 